\author{
ENGIN ARIK \\ Medipol University, Istanbul
}

\title{
AN EXPERIMENTAL APPROACH TO BASIC WORD ORDER IN TURKISH INTRANSITIVES
}

\begin{abstract}
This study offers an experimental perspective to investigate the word order and animacy effects of intransitives in Turkish, an agglutinative language with a canonical, flexible Subject-Object-Verb order. Four experiments were conducted to investigate a total of 528 Turkish speakers' acceptability judgments using rating scales (Experiments 1 and 3; 7-point Likert scales) and forced choice tasks (Experiments 2 and 4; choosing one of two sentences) for various orders of linguistic forms in a simple intransitive sentence. Results from scalar acceptability judgments showed that there were significant main effects of order and subject, indicating that participants gave significantly higher ratings to SV sentences than VS sentences and that their ratings changed significantly according to the animacy of the subjects. Results from the forced choice tasks showed that participants preferred SV sentences to VS sentences. These findings suggest that Turkish speakers prefer SV order over VS order even though both are readily available.
\end{abstract}

Key words: word order, Turkish, experimental linguistics

Word order is one of the most studied topics in languages from various typological and sociolinguistic perspectives. Most studies on the topic have focused on word order in transitive sentences, i.e. the order of the subject (S), object (O), and verb (V), starting from Greenberg (1963). The present study contributes to this line of research by offering a new way to investigate variations by applying an experimental linguistic method to analyze word order in Turkish intransitive sentences, in which nouns in the subject position are manipulated according to their semantic categories. Turkish is an agglutinative,

Address for correspondence: Engin Arik, School of Humanities and Social Sciences, Department of Psychology, Medipol University, Elvanzade Cami Sokak 2, Istanbul, Turkey. E-mail: enginarik@enginarik.com 
pro-drop language from the Turkic language family. Its canonical word order is SOV, but it allows other orders as well (Erguvanli, 1984). The results of the present study, which is the first study on Turkish word order employing an experimental linguistic methodology, show that Turkish speakers prefer SV order over VS order and human subjects to non-human subjects, even though both orders are readily available and acceptable.

A simple transitive sentence has two nouns and a predicate. Some languages morphologically mark these two nouns as subject and object. Other languages leave them morphologically unmarked. For instance, Thai (dominantly SVO), Arára Karó (dominantly SOV), Quiegolani Zapotec (dominantly VSO), and Minangkabau (no dominant order), also called zero-marking languages, do not mark subject and object morphologically (see Sinnemäki, 2010 for an overview). A simple combination of predicate (verb), subject, and object results in six possible orders - SOV, SVO, OSV, OVS, VOS, and VSO - in transitive sentences. In some languages (such as Turkish) word order is relatively flexible; in others, however, it is relatively rigid (such as English). Research has shown that the unmarked word order in English is SVO in simple sentences and in subordination (Lehmann, 1978, but see LaPolla \& Poa, 2006). However, it is also possible to observe other word orders in marked sentences (see examples 1 a, b, c below)). Thus, Newmeyer $(2004,2005)$ proposed that rather than classifying languages as OV or VO, language-specific classifications should be adopted. Perhaps, these marked sentences can be explained by language-specific rules or on-line processing preferences of the speakers following Hawkins (2004).

(1) English examples from Newmeyer (2004, p. 190):

a. The last lecture Mary really hated. (OSV)

b. Drink the whole bottle, John never would. (VOS)

c. Away ran John. (VS)

Cross-linguistic studies have shown that the six possible orders are not equally represented in word languages because the most common orders are SOV and/or SVO in both spoken and sign languages, as well as i gestural productions. In an examination of 1,228 spoken languages, Dryer (2005) found that 497 have SOV order (e.g., Japanese) and 435 languages have SVO order (e.g., English). In addition, he found that 85 languages (e.g., Irish) have VSO order, 26 languages (e.g., Nias) have VOS order, 9 languages (e.g., Hixkaryana) have OVS order, and 4 languages (e.g., Nadëb) have OSV order. He also observed that 172 of the 1,228 languages do not have a dominant word order. In other words, about $76 \%$ of these spoken languages have either a predominantly SOV or SVO order. It has been hypothesized that perhaps the basic word order of the earliest language was SOV (e.g., Gell-Mann \& Ruhlen, 2011). Yet, there is also a tendency for SOV languages to become SVO languages over time 
(e.g., Vennemann, 1976). Studies have also been conducted on the basic word order in sign languages, showing that some sign languages have preferences for SOV and SVO orders, and yet others allow for variations (see Leeson \& Saeed, 2012 for an overview). It is quite interesting that SOV order is also found in gesture productions. For example, Goldin-Meadow et al. (2008) asked English, Turkish, Spanish, and Mandarin Chinese speakers to describe video recorded events without using language but gestures. They found that the order of gestures was similar to the SOV order in speech, regardless of the language.

Research on the basic word order of languages has also revealed that word order can be manifested in phrasal structures. Dryer $(1991,1992)$ showed that the order of noun phrases and adpositions in a language are affected by basic word order: adpositions come before noun phrases in VO languages, whereas noun phrases come before adpositions in OV languages (e.g., (2 a, b)). Moreover, copulas come before predicates in VO languages while predicates come before copulas in OV languages. Verb phrases follow the want-type of predicates in VO languages, while the want-type of predicates follow verb phrases in OV languages (e.g., $(3 \mathrm{a}, \mathrm{b}))$. Furthermore, word order is also manifested in the orders of tense marking and verb phrase; negation and verb phrase; complementizer, question particle, adverbial subordinator, and main clause; definite, plural, genitive markers and noun; relative clause and noun; standard of comparison and noun; and prepositional phrase, manner adverb, and verb. Abbreviations for all examples in the text are as follows: 1,2,3=person (e.g., $1=$ first), dat=dative, gen=genitive, Inf=infinitive, loc=locative, past=past tense marker, $\mathrm{pl}=$ plural, poss=possessive, $\mathrm{sg}=$ singular.

(2) a. masa-da table-LOC

b. on the table

(3) masa-nın table-GEN

üst-ün-de on-poss-LOC
Ali okul-a
gitmek
Ali school- DAT go-INF
b. Ali wanted to go the school
Turkish
English

English

Turkish

In addition to syntactic factors such as the order of the constituents, word order is also affected by semantic factors such as animacy. Research has already shown that considering animacy hierarchy (human $>$ animal $>$ inanimate, Silverstein, 1976; Comrie, 1989) is an important factor for nouns to take the role of agent in a sentence, NP ordering, definiteness (Ransom, 1977), gender systems, pronominalization (Dahl \& Fraufud, 1996), and topicalization (Givon, 1983). It was also found that animates such as humans are more capable of carrying the agent role than less animates such as animals, or inanimate objects such as tables, chairs, rocks, and so on (see also Dahl, 2008). 


\section{Previous studies on Turkish word order}

Turkish is a pro-drop language that allows all of the possible six word orders in a basic transitive sentence. All of the six orders of a sentence consisting of a subject, an object, and a predicate are grammatical in principle. For example, in (4) a kissing event is provided in six word orders, all of which are grammatical and acceptable. Yet, the basic predicate structure for kiss (Sefa, Melda), where Sefa is the subject and Melda is the object, is not affected by the change in the order of the words.

$\begin{array}{rlrlr}\text { (4) a. } & \text { Sefa } \quad \text { Melda-yı } & \text { öp-tü- } \varnothing & \text { (SOV) } & \text { Turkish } \\ & \text { Child } \quad \text { Melda-acc } & \text { kiss-past-3sg } & & \\ & \text { 'Sefa kissed Melda' } & & \\ \text { b. } & \text { Sefa öp-tü- } \varnothing \text { Melda-yı } & & \text { (SVO) } \\ \text { c. } & \text { Melda-yı Sefa öp-tü- } \varnothing & & \text { (OSV) } \\ \text { d. } & \text { Melda-yı öp-tü- } \varnothing \text { Sefa } & & \text { (OVS) } \\ \text { e. Öp-tü- } \varnothing \text { Sefa Melda-yı } & & \text { (VSO) } \\ \text { f. OOp-tü- } \varnothing \text { Melda-yı Sefa } & & \text { (VOS) }\end{array}$

However, the uses of these word orders are restricted due to a variety of reasons. According to Erguvanlı (1984), basic Turkish word order is SOV and can be manipulated by pragmatic factors: when the NP is at the beginning of the sentence, it is in the topic position. It appears that constituents are in the focus position but carry background information when they come after the verb. The picture seems more complicated than this due to prosody and information structure (e.g., İşsever, 2003; Kılıçaslan, 2004; Özge \& Bozsahin, 2010). Kılıçaslan (2004) argued against assigning specific positions such as topic, focus, and background information with regard to the verb in Turkish. It appears that positions carrying information structure are not only affected by word order, but also phonology and intonation (İssever, 2003). Following this, some other restrictions and disagreements have also been revealed (see Göksel, 2013; for a summary). For example, interpretations of the scope of the quantifiers seem to be affected by the position of quantified nouns with regard to the main verb.

Nevertheless, variations in word order have not only been observed in adult language, but also in child language and child-directed language (Aksu-Koç \& Slobin, 1985; Küntay \& Slobin, 2002). Of the six possible word orders, SOV occurred in $46 \%$ of the data from child language and $48 \%$ in child-directed speech in natural conversation (Slobin, 1982). The flexibility of word order was also observed in narration. Aksu-Koç (1994) examined narratives from a picture book, The Frog Story, collected from children and adult Turkish speakers, and found that pro-drop sentences constitute about $50 \%$ of the data $(\mathrm{OV}, \mathrm{VO}$, and $\mathrm{V})$, while SOV and SV orders together were about $40 \%$ of the data from children and adults. 


\section{Present study: An experimental approach to basic word order in Turkish}

Previous research applying classical methods such as grammaticality judgments, insights, and narrative data has indicated that Turkish has a basic SOV word order, which allows variations to a great extent. It seems that Turkish word order is very much affected not only by syntactic operations, but also by information structure and prosody. Therefore, these findings call for new methods to further explore word order in Turkish. The present study is the first attempt to use an experimental linguistic methodology to provide further evidence for the most common word order in Turkish. Methods such as insights and grammaticality judgments often generate binary responses: Grammatical or Ungrammatical. Reaching consensus on a response can be problematic since insights and grammaticality judgments may differ from person to person. However, experimental linguistic methods are methods used to collect data on the basis of participant acceptability judgments. These judgments are often made using continuous measures such as Likert-type of scales where participants - not the experimenters - make judgments of varying degrees, from the least acceptable to the most acceptable. This methodology can also act as a tool to manipulate a variety of factors and investigate linguistic elements in a more controlled environment to further test linguistic phenomena. In the last decade these methods have gained more prominence in linguistics, perhaps starting with Sprouse (2007). Yet, this methodology has its shortcomings. It is almost impossible to present participants with sentences including all types of manipulations due to time limitations and fatigue of participants. . Moreover, there is no previous study on Turkish employing this methodology. Therefore, the present study limits its scope: It focuses only on intransitives, leaving a similar study on transitives to future research.

The present study used written language to control prosody and focus on two factors alone, i.e., all possible orders and semantics. For the basic word order, we followed Dryer's typological classification: OV vs. VO in transitives and SV vs. VS in intransitives (Dryer, 2013). This typology predicts four types of languages according to their basic word orders: OV and SV languages, OV and VS languages, VO and SV languages, and VO and VS languages. Therefore, focusing on only intransitives, the study assumes the two types of word order, SV and VS, and manipulates constituents accordingly. In addition to the order of the constituents, this study adopted animacy as a semantic factor including humans/animals/inanimates as subjects. We expected that both the syntactic and the semantic factor will affect the preferences for word order; i.e., Turkish speakers will prefer SV order over VS order and human subjects more than animal or inanimate subjects. Below we report four experiments to test our hypotheses that Turkish speakers' preference for SV order over VS order which 
interacts with animacy of the nouns in the subject position. Experiment 1 (SV vs. VS and Human vs. Animal) is a study on acceptability judgments of intransitive sentences with basic verbal predicates such as Adam düştü 'A/the man fell' while Experiment 2 is a forced-choice experiment on the same sentences. Experiment 3 (SV vs. VS and Human vs. Animal vs. Vehicle vs. Fruit) is another acceptability judgment study focusing on sentences with basic motion events such as Adam geldi 'A/the man came' while Experiment 4 is a forced-choice experiment using the sentences from Experiment 3.

\section{Experiment 1: Intransitive sentences with basic verbal predicates}

It was hypothesized that: 1) Turkish speakers would prefer SV order to VS order; and 2) the semantic category of the subjects affects speakers' judgments for SV over VS. It was expected that the order of the constituents and animacy interact with each other. Therefore, SV ordered sentences with human subjects might get higher ratings than those with animal subjects.

\section{Participants}

A total of 157 native speakers of Turkish (137 females) participated in this experiment. Their ages ranged from 18-53 years old, with an average age of 27 at the time of the study. Thirty-nine participants were students enrolled in university, 38 were graduates of a university, 28 were masters-level graduate students, 31 held an MA/MSc degree, and 21 were either doctoral students or held a doctoral degree. All of them were native speakers of Turkish and participated in the study voluntarily. None of the participants studied linguistics at a university.

\section{Materials}

Intransitive sentences using the past tense form -DI were generated according to a $2 \times 2$ repeated measures within-subjects design. There was a total of 24 test sentences. The first factor was Order with two levels (Subject-Verb vs. Verb-Subject). The second factor was Subject Type with two levels (Human vs. Animal). For Human Subject Type, two common nouns, adam 'man' and kadın 'woman', were chosen. For Animal Subject Type, two common animals, kedi 'cat' and köpek 'dog', were chosen. In addition, for the testing items, common verbs such as the action verbs düşmek 'to fall' and oturmak 'to sit,' verbs of emotion ağlamak 'to cry' and gülmek 'to smile,' and the animate verbs uyumak 'sleep' and bakmak 'look' were chosen. All of the possible orders were then generated using these verbs and nouns. The first two sentences were fillers with inanimate subjects in the two word orders for intransitives. Therefore, these sentences were also used as warm-up items for the participants. Apart from the warm-up items, the sentences were randomly ordered. 
Four examples from a token set are given below. Note that Turkish does not have a definite or gender marker.

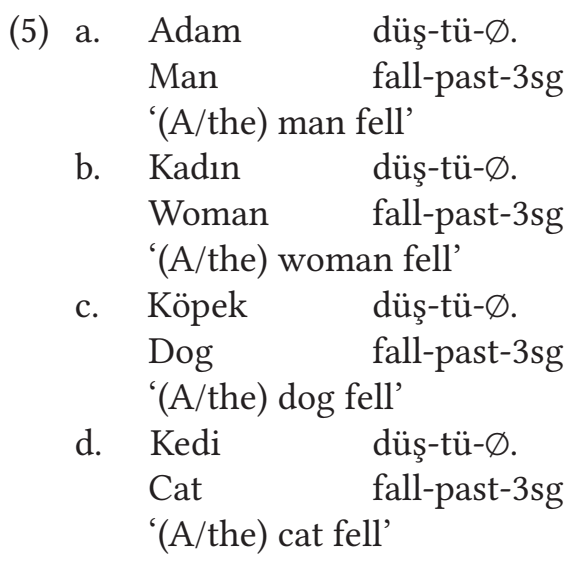

\section{Procedure}

In order to reach as many participants from various ages and education backgrounds as possible, the study was conducted online. Recruitment was announced on social media and was accessible for about a week. After answering three demographic questions about age, gender, and education level, participants were asked to rate the constructed sentences from 0 (inappropriate) to 6 (most appropriate) on a 7-point Likert scale with reference to everyday Turkish. The instructions stated that there was no right or wrong answer, and asked participants to rate the sentences according to 'Turkish spoken on the streets' rather than the Turkish that is taught in schools. Participants received the testing items one-by-one and were allowed to view the sentences as many times as they wished. They participated in this study voluntarily and could not be identified by name. Each session lasted about 5 minutes.

\section{Results}

Descriptive statistics for Experiment 1 are given in Figure 1. There were 33 missing responses (out of 3,768 testing item responses) but no missing data, i.e. each condition was responded to at least once per participant (missing responses were evenly distributed).

A repeated measures ANOVA was conducted to examine the within-subject effects of word order and subject type on participants' sentence ratings. Results from Experiment 1 showed a significant main effect of Order, indicating that participants rated SV sentences $(M=5.35, S D=0.06)$ significantly higher than VS sentences $(M=3.66, S D=0.14), F(1,156)=157.597, p<0.0001$. 
Figure 1. Means and standard deviations of the four conditions in intransitive sentences with the basic verbal predicates

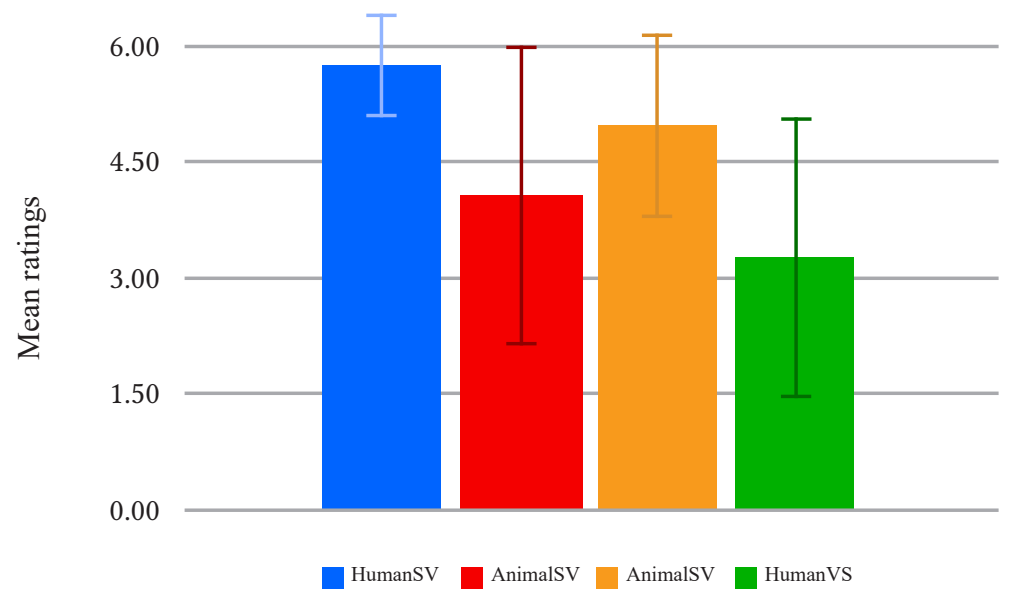

There was also a significant main effect of Subject Type: Human $M=4.90$, $S D=0.90 ;$ Animal $M=4.11, S D=0.10, F(1,156)=108.271, p<0.0001$, which indicated that participants gave significantly higher ratings to sentences with human subjects over those with animal subjects. There was no interaction between Subject Type and Order. Note that in Experiment 1 (and Experiment 3) VS sentences or non-human subjects did not receive either absolute or near zero scores, though the findings indicate that these VS sentences or non-human subjects are significantly less acceptable than SV sentences or human subjects.

\section{Experiment 2: Forced Choice}

In order to further investigate basic word order in Turkish intransitive sentences, a separate experiment, applying forced-choice procedures, was conducted.In forced-choice experiments participants are asked to pick one option over another given that there are two options. Therefore, because the options are binary, responses would be similar to traditional grammaticality judgments. The main difference between them lies in the way quantitative analysis could be conducted on the forced-choice experiments but not on grammaticality judgments. Forced-choice experiments can further provide evidence for the judgments by the participants who made acceptability judgments using continuous measures in acceptability judgments. In Experiment 1, it was found that the Turkish speakers gave higher ratings to the SV sentences than the VS sentences and sentences with human subjects than animal subjects. When 
asked to judge two similar sentences, do the Turkish speakers make similar judgments? Aiming at answering this question, adopting the same Hypothesis 1 and Hypothesis 2, Experiment 2 was conducted.

\section{Participants}

A total of 138 native speakers of Turkish ( 84 females) participated in this study. Their ages ranged 18 to 65 with an average age of 28.39 at the time of the study. Thirty-one participants were students enrolled in university, 28 had graduated from a university, 25 were masters-level graduate students, 23 held an MA/MSc degree, and 28 of them were either doctoral students or held a doctoral degree. All of them were native speakers of Turkish and participated in the study voluntarily. None of the participants studied linguistics at a university.

\section{Materials}

Experiment 2 adopted the same design as Experiment 1. Seven pairs of 14 sentences were randomly ordered, in which there were 8 testing items and 6 filler items with two words such as Babam öğretmen 'My father is a teacher' and Elma kırmiz1 '(A/the) apple is red'. Each pair contained the same words in two different random orders: SV order and VS order.

\section{Procedure}

Experiment 2 used the same procedure as Experiment 1. However, instead of rating the sentences, participants were asked to choose one sentence over another in the pair, i.e. responding to the question of Hangisi daha uygun? (Which one is more appropriate?). It took about 3 to 5 minutes to collect data from a participant. A binary coding system was used: When participants picked an SV ordered sentence, their responses were coded as 1; otherwise, they were coded as 0.) numbers do not carry values but are rather used to categorize the data

\section{Results}

The frequencies of word order choice are given in Figure 2. There were only 3 missing responses out of 1,104 testing item responses. The results from Experiment 2 showed that participants overwhelmingly chose SV sentences $(89.25 \%)$ over VS sentences (10.75\%). Because a binary coding system was used, a non-parametric analysis, Cochran's Q, was conducted. The results indicated that the distribution of choosing SV order over VS order was significantly different with respect to Subject, $X 2(7, N=135)=31.726, p=0.000$.

Because there was an overall significant difference, pairwise comparisons were conducted. Separate Cochran's Q analyses indicated that participants' choices significantly differed across sentences with human subjects (SV 80.4\% vs. VS $92.0 \%, X 2(3, N=136)=12.973, p=0.005)$, but not across those with 
Table 1. The Eight Testing Items (intransitives with the basic verbal predicates) and Participants' SV Preferences (Experiment 2)

\begin{tabular}{lllc}
\hline \multicolumn{1}{c}{ SV } & VS & English & SV preferences (\%) \\
\hline Adam ağladı. & Ağladı adam. & '(A/the) man cried.' & $111(80.4 \%)$ \\
Kadın düştü. & Düştü kadın. & '(A/the) woman fell.' & $115(83.3 \%)$ \\
Adam oturdu. & Oturdu adam. & '(A/the) man sat.' & $126(92.0 \%)$ \\
Kadın gülümsedi. & Gülümsedi kadın. ' '(A/the) woman smiled.' & $122(89.1 \%)$ \\
Köpek ağladı. & Ağladı köpek. & '(A/the) dog cried.' & $126(91.3 \%)$ \\
Kedi düştü. & Düştü kedi. & '(A/the) cat fell.' & $129(94.2 \%)$ \\
Köpek oturdu. & Oturdu köpek. & '(A/the) dog sat.' & $128(92.8 \%)$ \\
Kedi gülümsedi & Gülümsedi kedi. & '(A/the) cat smiled.' & $126(91.3 \%)$ \\
\hline
\end{tabular}

animal subjects (SV 91.24\% vs. VS 94.16\%, $X 2(3, N=137)=1.265, p>0.05)$. Moreover, a closer examination of sentences with human subjects revealed significant differences between Adam ağladı '(A/the) man cried' (80.4\%) and Adam oturdu '(A/the) man sat' ( $92 \%), X 2(1, N=137)=9.846, p=0.002$; between Adam ağladı '(A/the) man cried' (80.4\%) and Kadın gülümsedi '(A/the) woman smiled' (89.1\%), $X 2(1, N=137)=4.5, p=0.034$; and between Kadın düştü '(A/the) woman fell' (83.3\%) and Adam oturdu '(A/the) man sat' (92\%), $X 2(1, N=137)=6, p=0.014$. There were no other significant differences among sentences with human subjects.

The comparisons of responses to the two subjects with the same verb revealed that participants' choices significantly differed between Adam ağladı '(A/the) man cried' (80.4\%) and Köpek ağladı '(A/the) dog cried' (91.3\%), $X 2(1, N=138)=9, p=0.003$; and between Kadın düştü '(A/the) woman fell' (83.3\%) and Kedi düştü '(A/the) cat fell' (94.2\%), X2(1, N=137) = 11.842, $p=0.001$. There were no other significant differences between these sentences.

\section{Experiment 3: Intransitive sentences with basic motion events}

Experiments 1 and 2 showed that 1) the Turkish speakers rated the SV sentences higher than the VS sentences and 2) they preferred sentences with the SV order more than those with the VS order. Experiments 1 and 2 also 
showed that the Turkish speakers' judgments seemed to be affected by the animacy of the subjects. One could suspect that the animacy effect (human > animal > inanimate, Silverstein, 1976; Comrie, 1989) found in Experiment 1 and 2 might be related to the predicates in use, i.e., the verbs düşmek 'to fall' and oturmak 'to sit,' verbs of emotion ağlamak 'to cry' and gülmek 'to smile,' and the animate verbs uyumak 'sleep' and bakmak 'look'. Following this line of query, Experiment 3 further investigated the animacy effect on basic word order in Turkish intransitive sentences. In this experiment the sentences formed basic motion event predicates, i.e., gelmek 'to come', gitmek 'to go', and durmak 'to stop' since these acts can be equally applicable to both humans and animals. Nevertheless, previous research has shown that the animacy of nouns in the subject role can affect the word order of the constituents (human > animal > inanimate, Silverstein, 1976; Comrie, 1989). In order to further examine this, two groups of beings that can be in motion (i.e., vehicles) and that can be put in motion (i.e., round fruits), were added to Experiment 3. Experiment 3 adopted the same hypotheses as Experiment 1: that Turkish speakers would 1) prefer SV order to VS order and 2) prefer human subjects to non-human subjects.

\section{Participants}

A total of 106 native speakers of Turkish (94 females) participated in this experiment. Data from two participants were excluded because they did not give permission for use of their data. The age range of participants was 19 to 60 with an average age of 29.50 at the time of the study. Twentyone participants were students enrolled in university, 27 were graduates of a university, 17 were masters-level graduate students, 21 held an MA/MSc degree, and 19 of them were either doctoral students or held a doctoral degree. All of them were native speakers of Turkish and participated in the study voluntarily. None of the participants studied linguistics at a university.

\section{Materials}

Intransitive sentences with basic motion event predicates using the past tense form -DI were generated according to a $2 \times 4$ repeated measures withinsubjects design. The first factor was Order with two levels (Subject-Verb vs. Verb-Subject) and the second factor was Animacy with four levels (Human vs. Animal vs. Vehicle vs. Fruit). All nouns were common nouns: humans adam 'man,' kadın 'woman;' animals at 'horse,' koyun 'sheep;' vehicles araba 'car,' kamyon 'truck;' and, fruits elma 'apple', and portakal 'orange.' Three motion predicates were used: gelmek 'to come', gitmek 'to go', and durmak 'to stop.' A total of 144 (24 nouns x 3 verbs x 2 word orders) tokens were generated. Six examples from a token set were given below. 


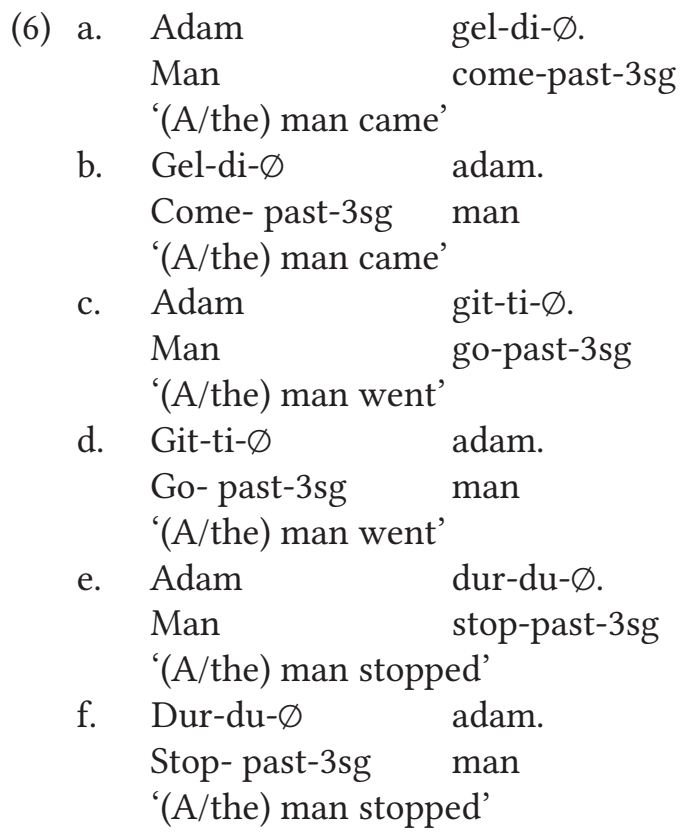

To equally represent each condition, 24 testing items were randomly selected. Additionally, 14 more sentences were generated and used as fillers. Overall, the questionnaire contained a set of 38 randomly ordered sentences, where the first two were fillers.

\section{Procedure}

Experiment 3 used the same procedure as Experiment 1.

\section{Results}

The descriptive statistics of Experiment 3 are given in Figure 2. There were 13 missing responses (out of 4,028 testing item responses), but no missing data, i.e., each condition was responded to at least once per participant. The analyses provided supporting evidence for the two hypotheses.

A repeated measures ANOVA was conducted to examine the within-subject effects of word order and subject type on participants' sentence ratings. The results from Experiment 3 showed a significant main effect of Order, indicating that participants rated SV sentences $(M=4.59, S D=0.08)$ significantly higher than VS sentences $(M=3.11, S D=0.14), F(1,105)=154.648, p<0.0001$.

There was also a significant main effect of Subject: Human $M=4.66$, $S D=0.09$; Animal $M=4.29, S D=0.12$; Vehicle $M=4.43, S D=0.10$; and Fruit $M=2.02, S D=0.16, F(3,315)=226.451, p<0.0001$. Pairwise comparisons showed that participants rated sentences with human subjects significantly higher than those with animals $(p<0.0001)$, vehicles $(p=0.001)$, and fruits 
Figure 2. Means and standard deviations of the four conditions in intransitive sentences with basic motion events

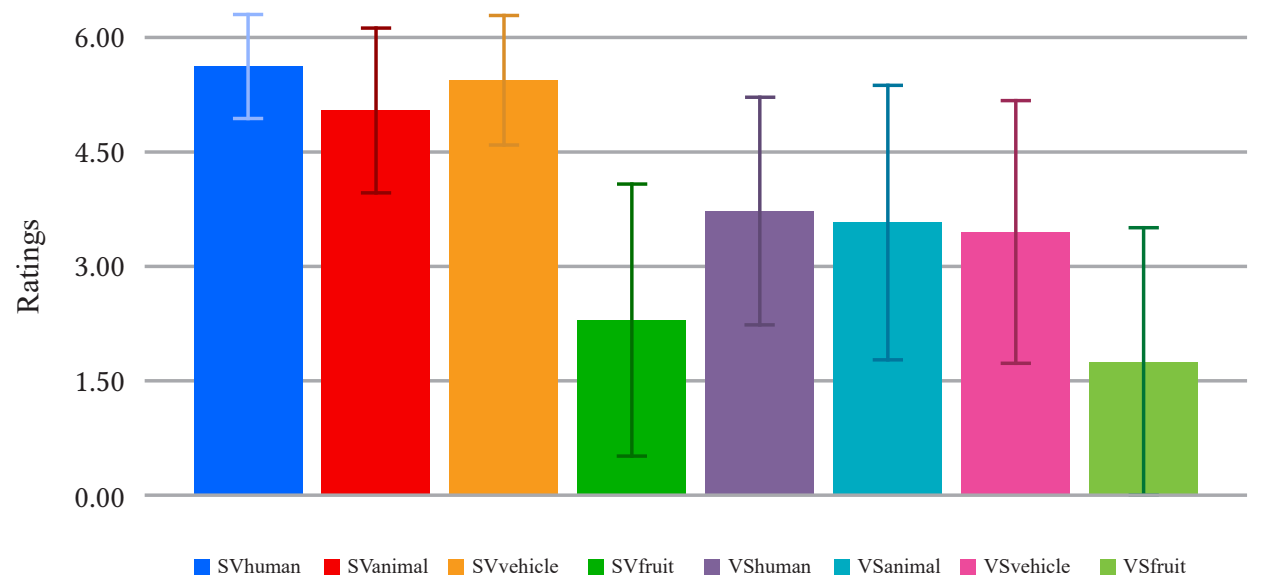

$(p<0.0001)$. Furthermore, participants rated sentences with animal subjects and with vehicle subjects significantly higher than fruit subjects $(p<0.0001$ for each). The difference between ratings of sentences with animal subjects and those with vehicle subjects did not reach statistical significance $(p=0.08)$. There was also an interaction between Subject and Order, $F(3,315)=49.053, p<0.0001$.

\section{Experiment 4: Forced choice with basic motion events}

Experiment 2 was a forced choice version of Experiment 1. Similarly, Experiment 4 was a forced choice version of Experiment 3 to further examine Turkish speakers' word order preferences in intransitives. Experiment 4 adopted the same hypothesis as Experiment 2: that Turkish speakers would prefer SV order to VS order.

\section{Participants}

A total of 127 native speakers of Turkish (97 females) participated in this study. Their ages ranged from 18 to 60 with an average age of 31.99 at the time of the study. Twenty-seven participants were students enrolled in university, 40 had graduated from university, 12 were masters-level graduate students, 20 held an MA/MSc degree, and 21 were either doctoral students or held a doctoral degree. All of them were native speakers of Turkish and participated in the study voluntarily. None of the participants studied linguistics at a university. 


\section{Materials}

Experiment 4 adopted a design similar to Experiment 3. Fifteen sentences were organized into pairs and randomly ordered, of which 8 contained testing items and 7 filler items with two words such as Taş yuvarlandı '(A/the) rock rolled (down)' and Biz yürüdük 'We walked.' The testing items consisted of four subject types (adam/kadın 'man/woman,' inek/öküz 'cow/bull', araba/kamyon 'car/truck', and elma/portakal 'apple/orange') and two motion verbs in the past tense (gitmek 'to go' and gelmek 'to come'). Each pair contained the same words in two different orders: SV or VS.

\section{Procedure}

Experiment 4 used the same procedure as Experiment 2. Participants were asked to choose one sentence over another given in a pair by responding to the question, Hangisi? (Which one?). Each participant spent about 3 to 5 minutes to complete the experiment. Experiment 4 used the same binary coding system as Experiment 2.

\section{Results}

The frequencies of word order choice are given in Figure 2. There were only 3 missing responses out of 1,104 testing item responses. The results from Experiment 4 showed that participants preferred SV sentences (83.36\%) to VS sentences (16.63\%). Cochran's Q showed that the distribution of choosing SV order over VS order was significantly different with respect to Subject, $X 2(7, N=124)=98.734, p<0.0001$.

Cochran's Q analyses indicated that participants' choices significantly differed across sentences with 'come' (95.3-88.2-92-83.5\%, $X 2(3, \mathrm{~N}=124)=10.465, p=0.015)$ and those with 'go' (85-71.7-90.6-60.6\%, $X 2(3, \mathrm{~N}=124)=47.287, p<0.0001)$. Because there were significant differences, pairwise comparison tests were conducted. The results showed significant differences between Adam geldi '(A/the) man came' (95.3\%) and İnek geldi '(A/the) cow came' $(88.2 \%), X 2(1, N=127)=4.263, p=0.039$, and Adam geldi '(A/the) man came' (95.3\%) and Elma geldi '(A/the) apple came' (83.5\%), $X 2(1, N=126)=8.167, p=0.004$, but not between the other pairs across sentences with 'come'.

The results also showed significant differences between Kadın gitti '(A/the) woman went' (85\%) and Öküz gitti '(A/the) bull went' (71.7\%), $X 2(1, N=127)=9.323, p=0.002$; Kadın gitti '(A/the) woman went' $(85 \%)$ and Portakal gitti '(A/the) orange went' $(60.6 \%), X 2(1, N=127)=20.447, p=0.000$; Öküz gitti '(A/the) bull went' (71.7\%) and Araba gitti '(A/the) car went' (90.6\%), $X 2(1, N=127)=18.000, p=0.000$; Öküz gitti '(A/the) bull went' $(71.7 \%)$ and Portakal gitti '(A/the) orange went' $(60.6 \%), X 2(1, N=127)=4.900, p=0.027$; 
Table 2. The Eight Testing Items (intransitives with the basic motion events) and Participants' SV Preferences (Experiment 4)

\begin{tabular}{llll}
\hline SV & VS & English & SV preferences (\%) \\
\hline Adam geldi. & Geldi adam. & '(A/the) man came.' & $121(95.3 \%)$ \\
Kadın gitti. & Gitti kadın. & '(A/the) woman went.' & $108(85.0 \%)$ \\
İnek geldi. & Geldi inek. & '(A/the) cow came.' & $112(88.2 \%)$ \\
Öküz gitti. & Gitti öküz. & '(A/the) woman went.' & $91(71.7 \%)$ \\
Kamyon geldi. & Geldi kamyon. & '(A/the) truck came’ & $115(92.0 \%)$ \\
Araba gitti. & Gitti araba. & '(A/the) car went.' & $115(90.6 \%)$ \\
Elma geldi. & Geldi elma. & '(A/the) apple came’ & $106(83.5 \%)$ \\
Portakal gitti. & Gitti portakal. & '(A/the) orange went.' & $77(60.6 \%)$ \\
\hline
\end{tabular}

and Araba gitti '(A/the) bull went' (90.6\%) and Portakal gitti '(A/the) orange went' $(60.6 \%), X 2(1, N=127)=30.083, p<0.0001$, but not between other pairs of sentences with 'go'.

Another set of Cochran's $Q$ analyses showed that participants' choices significantly differed across sentences with human subjects (between $95.3-85 \%, X 2(1, N=127)=8.895, p=0.003)$, animal subjects $(88.2 \%$ vs. $71.7 \%$, $X 2(1, N=127)=15.207, p<0.001)$, and animal subjects $(83.5 \%$ vs. $60.6 \%$, $X 2(1, N=127)=21.564, p<0.0001)$, but not fruit subjects $(p>0.05)$.

\section{Conclusion}

The current study investigated the basic word order structure in Turkish intransitives from an experimental linguistics perspective. It reported the findings of four experiments in which native speakers of Turkish were asked to rate intransitive sentences with basic verbal predicates and basic motion events, and were also asked to pick one sentence over another which differed only in the order of the constituents. The results from the four experiments provided supporting evidence for the two stated hypotheses: 1) Turkish speakers prefer SV order to VS order and 2) their preferences are affected by the semantic category of the subjects. 
Previous research has shown that based on intuitive data, Turkish has a canonical OV order in transitive sentences (Erguvanli, 1984), and narrative data from adults, child-directed speech, and children showed variations in the order of the constituents (Aksu-Koç, 1994; Aksu-Koç \& Slobin, 1985; Küntay \& Slobin, 2002; Slobin, 1982). Using the experimental linguistic methodology, this study provided further evidence not only for the flexibility in the word order even in Turkish intransitives but also preference for SV over VS, following Dryer's typological distinction (2013). The findings from the acceptability judgments (Experiments $1 \& 3$ ) and the forced-choice tasks (Experiments $2 \& 4$ ) provided supporting evidence for Hypothesis 1. Both SV and VS orders in Turkish intransitives were readily available and grammatical, but native speakers of Turkish preferred SV order significantly over VS order in intransitives with simple verbal predicates and basic motion events. Future research will test these findings in other OV languages such as Japanese to examine order preferences.

Previous research on Turkish word order did not consider a possible effect of semantics even though the animacy hierarchy (human > animal > inanimate) is an important factor for nouns when it comes to taking an agent role in a sentence (Silverstein, 1976; Comrie, 1989; Dahl, 2008). The findings from the acceptability judgments (Experiments $1 \& 3$ ) and the forced-choice tasks (Experiments $2 \& 4$ ) also provided supporting evidence for Hypothesis 2. Animacy of nouns in the subject positions played a significant role in the Turkish speakers' judgments. These findings indicate Turkish speakers prefer sentences with human subjects to those with animal subjects. Future research will test these findings in other languages such as English to observe the animacy effect.

There are some limitations of the present study. A limited set of nouns and predicates makes it difficult to generalize the results. Because the present study was the first study on Turkish intransitives employing an experimental linguistic methodology, the findings still present valuable observations on the Turkish preferences for word order. Yet, future studies should aim at expanding the token set of nouns and predicates to better generalize the results. Another limitation of the present study is that only written sentences were used to obtain data from the participants. In spoken language there are effects of prosody and intonation, which may alter the order of the constituents in Turkish as previous studies have already shown (e.g., İsssever, 2003; Kılıçaslan, 2004; Özge \& Bozsahin, 2010). Future research should investigate spoken language and explore potential effects of prosody and intonation.

The present study focused only on intransitive sentences with a limited set of action verbs (düssmek 'to fall' and oturmak 'to sit'), verbs of emotion (ağlamak 'to cry' and gülmek 'to smile'), and motion verbs (gelmek 'to come' and gitmek 'to go'). In addition to transitivity, animacy of the subjects was manipulated with humans and animals. Although syntactic roles of nouns were kept constant, i.e. they were all subjects, their semantic roles were varied, especially 
in the first two experiments. For example, the arguments of the verb düşmek 'to fall' were undergoers, whereas those of oturmak 'to sit' and motion verbs were agents. Moreover, the arguments of emotion verbs were experiencers. Similarly, volition of the subjects varied in the basic motion events: Humans and animals but not vehicles or fruits can move by themselves under normal circumstances. A future study, therefore, should systematically explore a potential effect those semantic roles might have on speakers' preferences for the basic word order.

\section{References}

Aksu-Koç, A.A. (1994). Development of linguistic forms: Turkish. In R.A. Berman \& D.I. Slobin (Eds.), Relating Events in Narrative: A Crosslinguistic and Developmental Study (pp. 329-392). Hillsdale, NJ: Lawrence Erlbaum Associates.

Aksu-Koç, A.A. \& Slobin, D.I. (1985). Acqusition of Turkish. In D.I. Slobin (Ed.), The Crosslinguistic Study of Language Acqusition. Vol. 1: The Data (pp. 839-878). Hillsdale, NJ: Lawrence Erlbaum Associates.

Comrie, B. (1989). Language Universals and Linguistic Typology. Oxford, UK: Blackwell.

Dahl, Ö. (2008). Animacy and egophoricity: Grammar, ontology and phylogeny. Lingua, 118 (2), 141-150.

Dahl, Ö. \& Fraufud, K. (1996). Animacy in grammar and discourse. In T. Fretheim \& J.K. Gundel (Eds.), Reference and Referent Accessibility (pp. 47-66). Philadelphia, PA: John Benjamins.

Dryer, M.S. (1991). SVO Languages and the OV/VO Typology. fournal of Linguistics, 27 (2), 443-482.

Dryer, M.S. (1992). The Greenbergian word order correlations. Language, 68 (1), 81-138.

Dryer, M.S. (2005). Order of subject, object, and verb. In M. Haspelmath, M.S. Dryer, D. Gil, \& B. Comrie (Eds.), The World Qtlas of Language Structures (pp. 330-333). Oxford, UK: Oxford University Press.

Dryer, M.S. (2013). Against the six-way order typology, again. Studies in Language, $37(2), 267-301$.

Erguvanli, E.E. (1984). The Function of Word Order in Turkish. Berkeley, CA: University of California Press.

Gell-Mann, M. \& Ruhlen, M. (2011). The origin and evolution of word order. Proceedings of the National Academy of Sciences, 108 (42), 17290-17295.

Givon, T. (1983). Topic Continuity in Discourse: A Quantitative Crosslinguistic Study. Philadelphia, PA: John Benjamins.

Goldin-Meadow, S., So, W., Ozyurek, A., \& Mylander, C. (2008). The natural order of events: How speakers of different languages represent events nonverbally. Proceedings of the National Academy of Sciences, 105 (27), 9163-9168. 
Göksel, A. (2013). Free word order and anchors of the clause. SOAS Working Papers in Linguistics, 16, 3-25.

Greenberg, J.H. (1963). Some universals of grammar with particular reference to the order of meaningful elements. In J.H. Greenberg (Ed.), Universals of Grammar (pp. 73-113). Cambridge, MA: MIT Press.

Hawkins, J. A. (2004). Efficiency and Complexity in Grammars. Oxford, UK: Oxford University Press.

İşsever, S. (2003). Information structure in Turkish: The word order-prosody interface. Lingua, 113 (11), 1025-1053.

Kilıçaslan, Y. (2004). Syntax of information structure in Turkish. Linguistics, $42(4), 717-765$.

Küntay, A. \& Slobin, D.I. (2002). Putting interaction back into child language: Examples from Turkish. Psychology of Language and Communication, 6(1), 5-14. LaPolla, R.J. \& Poa, D. (2006). Describing word order. In F. Ameka, A. Dench, \& N. Evans (Eds.), Catching Language: The Standing Challenge of Grammar Writing (pp. 269-295). Berlin: Mouton de Gruyter.

Lehmann, W. (1978). English: A characteristic SVO language. In W. Lehmann(Ed.), Syntactic Typology: Studies in the Phenomenology of Language (pp.169-222). Austin, TX: University of Texas Press.

Leeson, L. \& Saeed, J.I. (2012). Word order. In R. Pfau, M. Steinbach, \& B. Woll (Eds.), Sign Language: An International Handbook (pp. 245-264). Berlin: Mouton de Gruyter.

Newmeyer, F. (2004). Against a parameter-setting approach to typological variation. Linguistic Variation Yearbook, 4 (1), 181-234.

Newmeyer, F. (2005). Possible and Probable Languages: A General Perspective on Linguistic Typology. Oxford, UK: Oxford University Press.

Ozge, U. \& Bozsahin, C. (2010). Intonation in the grammar of Turkish. Lingua, $120(1), 132-175$.

Ransom, E.N. (1977). Definiteness, Animacy, and NP Ordering. In E.N. Ransom, Proceedings of the 3rd Annual Meeting of the Berkeley Linguistics (pp. 418-429). Berkeley, CA.

Silverstein, M. (1976). Hierarchy of Features and Ergativity. In R.M.W. Dixon (Ed.), Grammatical Categories in Australian Languages (pp. 112-171). Canberra: Australian National University.

Sinnemäki, K. (2010). Word order in zero-marking languages. Studies in Language, 34 (4), 869-912.

Slobin, D.I. (1982). Universal and particular in the acquisition of language. In E. Wanner \& L.R. Gleitman (Eds.), Language Acquisition: The State of the Art (pp. 128-172). Cambridge, UK: Cambridge University Press.

Sprouse, J. (2007). A program for experimental syntax: Finding the relationship between acceptability and grammatical knowledge. Doctoral dissertation, University of Maryland, College Park, MD. 
Vennemann, T. (1976). Categorial grammar and the order of meaningful elements. In A. Juilland (Ed.), Linguistic Studies Offered to foseph Greenberg on the Occasion of his Sixtieth Birthday (pp. 615-634). Saratoga, CA: Anma Libri. 